FRBSF Working Paper 2002-08

\title{
Stylized Facts on Nominal Term Structure and Business Cycles: An Empirical VAR Study
}

\author{
Tao $\mathrm{Wu}^{*}$ \\ First draft: November 15, 2000 \\ This version: August 23, 2001
}

\begin{abstract}
This paper examines the importance of various macroeconomic shocks in explaining the movement of the term structure of nominal bond yields in the post-war U.S., as well as the channels through which such macro shocks influence the yield curve, using a structural Vector Autoregressive (VAR) model. The results show that the monetarypolicy and the aggregate-supply shocks are important determinants of the nominal term structure. Moreover, the monetary-policy innovations have a large but transitory effect on the nominal bond yields, primarily by changing the slope of the yield curve, and the aggregatesupply shocks from private sector have a more persistent effect on the level of the yield curve, but have little effect on the slope of the yield curve.
\end{abstract}

JEL Classification: C13, C22, E43, E44, E52

*I thank Christopher Sims, Stefan Krieger and Hua He for their insightful suggestions and comments. The views expressed herein are solely those of the author and not necessarily those of the Federal Reserve Bank of San Francisco or the Federal Reserve System. Email: tao.wu@sf.frb.org. Correspondence to: Tao Wu, Economic Research Department, Federal Reserve Bank of San Francisco, 101 Market Street, San Francisco, CA 94105. 


\section{Introduction}

Understanding how the macroeconomic fundamentals are related to term structure movements is essential to comprehending the behavior of the prices of the fixed-income securities, and also vitally important for valuation and arbitrage purposes in various financial markets. This paper examines the cyclical behavior of the term structure of nominal bond yields in the postwar U.S. I formulate and estimate an identified Vector Autoregressive (VAR) model, and find that the macroeconomic shocks, namely the monetary-policy and the aggregate-supply shocks, are important determinants of movement of the nominal term structure. Specifically, the monetary-policy innovations have a large but transitory effect on the nominal bond yields, primarily by changing the slope of the yield curve, and the aggregate-supply shocks from private sector have a more persistent effect on the level of the yield curve, but have little effect on the slope of the yield curve. Section 2 lays out the VAR model and describes the data, section 3 presents the results, and section 4 concludes.

\section{A Structural Vector Autoregressive (VAR) Model}

I use a recursive strategy to identify the monetary-policy innovations and other kinds of macro shocks, and examine the impulse responses of the nominal term structure to the macro shocks.

The term structure data are zero-coupon bond yields of maturities 1, 3, $6,12,24,36,48$, and 60 months, covering the period from January 1967 to December 1998. The long-term bond yields (12, 24, 36, 48, 60 months) are taken from Fama CRSP zero-coupon bond files, while the shorter maturity rates (1, 3, 6 months) are taken from Fama CRSP Treasury Bill files (1, 3, 6 months). To examine the movements of the yield curve and its co-movements with the macro variables during business cycles, we need to summarize the information contained in the shape of the yield curve. Following Evans and Marshall (1998), I do so by taking a quadratic approximation of the yield curve in each month. By regressing all interest rates at a given date on a constant, maturity, and squared maturity, I obtain the coefficient estimates of the intercept, slope and the curvature of the yield curve. Note that these coefficients are time-varying, since the regression only involves interest rates 
at a given date, and is re-estimated each month. ${ }^{1}$ The time series of the intercept, slope and curvature are then used in the VAR estimation.

The data vector of the macro variables is given by $Y_{t} \equiv(I P, E M, P C E$, $\left.M_{1}, F F, P C O M\right)^{\prime}$, where: IP denotes the logarithm of industrial production; EM denotes the logarithm of nonagricultural payroll employment in private sector; PCE denotes the logarithm of the personal consumption expenditures price index; M1 denotes the logarithm of the monetary aggregate M1; FF denotes the federal funds rate; and PCOM denotes the logarithm of the spot market price index for sensitive materials. All macro data are taken from Citibase, and are seasonally adjusted except for FF and PCOM.

I assume that the monetary authority uses the federal funds rate as its policy instrument. Moreover, I assume that the price level and real economic activity only respond to monetary policy with a one-month lag, except for the commodity prices, which are formed in auction markets, and therefore can respond to any news contemporaneously. On the other hand, the monetary authority observes the price level and real economic activity with a onemonth delay. This is because the measures of the price level and of real economic activity are compiled from survey data, and the surveys take time to compile and are available to the monetary authority only with a delay. I also assume that the bond market responds rapidly to the changes in all macro variables, but neither contemporaneous nor lagged bond yields affect the determination of the macro variables. ${ }^{2}$ With these assumptions I can then set up the following structural VAR: ${ }^{3}$

$$
\left[\begin{array}{ll}
a & 0 \\
c & 1
\end{array}\right]\left[\begin{array}{l}
Y_{t} \\
R_{j, t}
\end{array}\right]=\left[\begin{array}{ll}
A(L) & 0(L) \\
C(L) & D(L)
\end{array}\right]\left[\begin{array}{l}
Y_{t-1} \\
R_{j, t-1}
\end{array}\right]+\Sigma\left[\begin{array}{l}
\varepsilon_{Y, t} \\
\varepsilon_{R, t}
\end{array}\right]
$$

where $a$ is a lower-triangular square matrix with ones on the diagonal. The

\footnotetext{
${ }^{1}$ In more than half of the months the coefficient of determination $R^{2}$ is greater than 0.95 , and in most of the months $R^{2}$ is greater than 0.8. Therefore, the intercept, slope and curvature summarize the shape of the yield curve quite well.

${ }^{2}$ Essentially the nominal bonds are treated as redundant assets here, having no influences on the macro economy. In practice the long-term bond yields are frequently used as an indicator of the long-run inflation rate. However, if the 6-variable VAR, $a Y_{t}=A(L) Y_{t-1}+\Sigma \varepsilon_{Y, t}$, is sufficient in capturing the market's expectation process of the future inflation, then the long-term bond yields $R_{j, t}$ 's will have little additional forecasting power, and should not affect the determination of the macro variables $Y_{t}$.

${ }^{3}$ I thank Christopher A. Sims very much for his insightful suggestions in formulating the model.
} 
first three entries of the fifth row of $a$ are zeros, reflecting the fact that the monetary authority is not able to observe the current month's industrial production, employment, or price level. $c$ is a row vector; $A(L)$ is a matrix polynomial in the lag operator $L ; 0(L)$ is a column vector polynomial with all entries being zeros; $C(L)$ is a row vector polynomial and $D(L)$ is a scalar polynomial. $R_{j, t}$ is a scalar that denotes one of the1-month, 6-month, 12-month and 60-month nominal zero-coupon bond yields, or one of the estimated intercept, slope and curvature of the yield curve, and each time only one of these variables enters the system. The process $\left[\varepsilon_{Y, t}, \varepsilon_{R, t}\right]^{\prime}$ is an i.i.d. vector of mutually and serially uncorrelated structural shocks whose variance is the identity matrix. $\Sigma$ is a diagonal matrix. Since $Y_{t}$ 's do not respond to the innovations in bond market, the innovations in the macro variables $\varepsilon_{Y, t}$ 's are invariant when different kinds of $R_{j, t}$ enter the system. Next I estimate the structural VAR model and examine the impulse responses of yield-curve descriptors (including bond yields with different maturities as well as the intercept, slope and curvature of the whole yield curve) to those shocks. Variance decompositions are then performed to study the components of the bond-yield variability.

\section{Empirical Results}

The VARs are estimated over the sample period 1967:01 to 1998:12. Twelve lagged values are estimated in each equation, with the initial lags beginning in 1966:01. Figure 1 displays the impulse response functions of the macro variables to monetary-policy shocks and real output shocks. Bayesian Monte Carlo methods are used to compute $95 \%$ confidence bands. The confidence bands are displayed around the point estimates of the impulse responses functions. Both the impulse responses and the confidence bands are measured in percentage deviation from the non-stochastic steady state.

A one-standard-deviation, contractionary monetary-policy innovation leads to gradual decreases in the output level as well as in the price level, and an instant 53-basis-point increase in the federal funds rate. The response of federal funds rate rises to its maximum of 66 basis points in the next month before falling thereafter, and becomes trivial after six months of the initial shock. The federal funds rate response, therefore, is significant but transitory. The other variables' responses seem consistent with most economists' prior expectations for a monetary-policy shock. The increase in the federal funds 
rate causes gradual reductions in industrial production and employment, and causes the prices to decline over time. A positive, one-standard-deviation shock of output leads to an instant increase in industrial production and a gradual decrease in the price level. In response to such a positive output shock, there is an 11-basis-point increase in the federal funds rate in the next month. The response reaches its maximum of 28 basis points in the fifth month after the shock, and is still significant after two years.

Figure 2 shows the impulse responses of the bond yields and yield-curve descriptors to monetary-policy shocks and real output shocks. A one-standarddeviation, contractionary monetary-policy shock increases the one-month bond yield by approximately 38 basis points in the period when the shock occurs. This response is statistically significant. The one-month bond yield continues to climb in the following months, and then falls rapidly, with the effect of the shock dissipating in six months. The six-month, one-year and five-year bond yields display qualitatively similar patterns, although the magnitude of the response decreases as the maturity of the bond increases. The initial response of the five-year bond yield is only 8.75 basis points, and it dissipates rapidly in five months.

The impulse responses of the estimated intercept to a one-standarddeviation, contractionary monetary-policy shock are qualitatively and quantitatively very similar to those of the one-month bond yield. The slope of the yield curve decreases by $0.0094 \%$ in the next month after such a shock, ${ }^{4}$ and the effect gradually decreases to a trivial level in five months. The curvature of the yield curve also decreases slightly in response to such a monetary-policy innovation.

In a closely related work, Evans and Marshall (1998) construct three different identified VAR models to study the influences of monetary-policy innovations on the bond market. Their results, by and large, confirm the results I obtain. The impulse responses they reported of the macro variables and of nominal bond yields to monetary-policy innovations are very similar to the ones shown in the first column of Figure 1 and that of Figure 2. ${ }^{5}$ Their estimation shows that a one-standard-deviation contractionary monetarypolicy shock increases the one-month bond yield by a maximum of 30 basis

\footnotetext{
${ }^{4}$ The sample mean of slope during 1967 to 1998 is $0.0495 \%$. Thus the $0.0094 \%$ decrease in slope amounts to a relative change of $19 \%$ from its long-run mean.

${ }^{5}$ Evans and Marshall (1998) only report the impulse responses and variance decompositions associated with monetary-policy innovations. And those are the only results that I can compare my results with.
} 
points, and the responses dissipate in six to ten months. The longer-term bond yields display qualitatively similar patterns of impulse responses, and the magnitude of the response decreases as bond maturity increases. Therefore, the empirical patterns of impulse responses I obtain here are robust to different identification strategies.

In response to a positive, one-standard-deviation shock of output, the onemonth bond yield increases by 2.35 basis points, the six-month rate increases by 9.81 basis points, the one-year rates increases by 10.33 basis points, and the five-year rate increases by 7.39 basis points. The impulse responses of the bond yields to the output shocks are strongly persistent. Most of them are still significant even after fifteen to eighteen months. The impulse responses of the intercept are very similar to those of the one-month bond yield. The slope and the curvature increase in reaction to such a positive shock of output, although the magnitudes are smaller than their responses to a one-standarddeviation monetary-policy innovation.

To explicitly examine the magnitude of the bond-yield volatility that can be attributed to the macro shocks, consider variance decompositions displayed in Table 1. The table gives the point estimates of the fraction of the one-month-ahead, three-month-ahead, one-year-ahead, and two-yearahead conditional variance of the one-month, six-month, one-year, five-year bond and the yield-curve descriptors that are attributable to the monetarypolicy innovations and output shocks. Monetary-policy innovations account for $59.21 \%$ of the conditional variance of the one-month bond yield at the one-month horizon. This fraction decreases as bond-maturity increases, and only $5.19 \%$ of the conditional variance of the five-year bond yield at the onemonth horizon can be attributed to the monetary-policy innovations. The monetary-policy innovations also account for less and less fraction of the conditional variance of the bond yields as the forecasting horizon increases. At the three-month horizon, monetary-policy innovations account for $35.47 \%$ of the conditional variance of the one-month bond yield, $19.48 \%$ for the sixmonth bond yield, $11.80 \%$ for the one-year bond yield, and only $2.09 \%$ for the five-year bond yield. The fractions attributable to the monetary shocks are even less at the one-year horizon and two-year horizon. ${ }^{6}$

\footnotetext{
${ }^{6}$ The variance decompositions that Evans and Marshall (1998) obtain are a bit different from the ones reported in Table 1, because they have different choices of variables and different VAR models. And they only report the variance decompositions that are attributable to monetary-policy innovations. However the general results are the same as the ones I find: that the monetary-policy shocks account for significant fractions of
} 
Compared with the monetary-policy innovations, the shocks of real output account for a smaller fraction of the conditional variance at the short end of the yield curve, but account for a larger fraction for bonds with longer maturities. At the three-month horizon, the shocks of output account for $23.22 \%$ of the conditional variance of the one-month bond yield, $21.15 \%$ for the six-month bond yield, $23.78 \%$ for the one-year bond yield, and $13.07 \%$ for the five-year bond yield. The fractions attributable to the output shocks outweigh the fractions attributable to the monetary-policy shocks at the one-year horizon for every kind of bond yields. And the output shocks still account for significant fractions of error variance of all kinds of bond yields even at the two-year horizon, indicating a persistent effect on the bond market.

The pattern of the variance decompositions for the estimated intercept is very similar to the pattern for the one-month bond yield. For the estimated slope of the yield curve, the monetary-policy shocks account for $27.65 \%$ of its conditional variance at the one-month horizon, $22.02 \%$ at the three-month horizon, $8.75 \%$ at the one-year horizon and $13.12 \%$ at the two-year horizon. Monetary policy innovations account for significant fractions of the shortrun variability of the slope of yield curve. This suggests that monetary policy is an important determinant of the slope of the yield curve in the short run, as conjectured by authors such as Litterman and Scheinkman (1991) and Evans and Marshall (1998). The monetary-policy innovations also account for $16.74 \%$ of the conditional variance of the curvature at the one-month horizon and $17.63 \%$ at the three-month horizon, further showing their influence on the shape of the yield curve.

In summary, a contractionary monetary-policy shock transitorily increases the federal funds rate, decreases the output level and the price level. On the bond market, such a policy shock has a large and significant but relatively short-lived effect on short-term bond yields, with dissipating effect on bond yields with longer maturities. There is not a parallel upward shift of the term structure in response to the monetary contraction. Instead, the slope and the curvature of the yield curve decrease, so that the yield curve becomes flatter. On the other hand, a positive shock of real output gradually raises the federal funds rate, increases the output level and decreases the price level. It increases the bond yields and the magnitude of the increase is similar across different bond maturities. Its influences on the bond market

the conditional variances of bond yields, and such fractions decrease as both the bond maturity and the forecasting horizon increase. 
are quantitatively smaller than the impacts from the monetary-policy shock at the short horizon, but are larger at the longer horizon. In short, macro shocks play an important role in determining the term structure of nominal bond yields. Monetary-policy innovations have a large but transitory effect on the nominal bond yields, primarily by changing the slope of the yield curve, and the real output shocks from private sector have a more persistent effect on the level of the yield curve, but have little effect on the slope of the yield curve.

\section{Concluding Remarks}

This paper examines the importance of various macroeconomic shocks in explaining the movement of the term structure of nominal bond yields in the post-war U.S., as well as the channels through which such macro shocks influence the yield curve. The empirical results show that the monetarypolicy and the aggregate-supply shocks from the private sector are important determinants of the movement of the nominal term structure. Moreover, the results suggest that the monetary-policy innovations have a large but transitory effect on the nominal bond yields, primarily by changing the slope of the yield curve, and the aggregate-supply shocks from private sector have a more persistent effect on the level of the yield curve, but have little effect

on the slope of the yield curve. This provides strong evidence in support of Knez, Litterman and Scheinkman (1994)'s conjecture on the relation between the slope factor and the Federal Reserve policy, and is also consistent with the results in Wu (2001a, 2001b)'s general-equilibrium based simulation study.

\section{References}

[1] Evans C. L. and D. A. Marshall, 1998. "Monetary Policy and the Term Structure of Nominal Interest Rates: Evidence and Theory", CarnegieRochester Conference Series on Public Policy, 49, 53-111.

[2] Hamilton, J. D., 1994. Time Series Analysis, Princeton University Press.

[3] Knez, P., Litterman, R., and J. A. Scheinkman, 1994. "Explorations into Factors Explaining Money Market Returns", Journal of Finance, 49, 1861-1882. 
[4] Leeper, E. M., C. A. Sims and T. Zha, 1996. "What Does Monetary Policy Do?", Brookings Papers on Economic Activity, 1996 (2).

[5] Litterman, R., and J. A. Scheinkman, J., 1991. "Common Factors Affecting Bond Returns", Journal of Fixed Income, 1, 54-61.

[6] Wu, Tao, 2001a, "Macro Factors and the Affine Term Structure of Interest Rates ", Ph.D. dissertation, Yale University, 2001.

[7] —, 2001b, "Monetary Policy and Slope Factor in Empirical Term Structure Estimations", manuscript, Yale University, 2001. 


\section{Table 1: Fraction of Bond-yield Variability Explained by Monetary-policy and Output Shocks}

\begin{tabular}{|c|c|c|c|c|c|c|c|}
\hline & \multicolumn{4}{|c|}{ One-month Horizon } & \multirow[b]{2}{*}{ intercept } & \multirow[b]{2}{*}{ slope } & \multirow[b]{2}{*}{ curvature } \\
\hline & 1-month & 6-month & 1-year & 5-year & & & \\
\hline Monetary shocks & $59.21 \%$ & $35.61 \%$ & $24.06 \%$ & $5.19 \%$ & $50.09 \%$ & $27.65 \%$ & $16.74 \%$ \\
\hline \multirow[t]{2}{*}{ Output shocks } & $6.49 \%$ & $10.90 \%$ & $12.84 \%$ & $10.93 \%$ & $5.10 \%$ & $0.84 \%$ & $2.17 \%$ \\
\hline & \multicolumn{3}{|c|}{ Three-month Horizon } & 5-year & intercept & slope & curvature \\
\hline Monetary shocks & $35.47 \%$ & $19.48 \%$ & $11.80 \%$ & $2.09 \%$ & $29.32 \%$ & $22.02 \%$ & $17.63 \%$ \\
\hline \multirow[t]{3}{*}{ Output shocks } & $23.22 \%$ & $21.15 \%$ & $23.78 \%$ & $13.07 \%$ & $18.89 \%$ & $1.54 \%$ & $0.11 \%$ \\
\hline & \multicolumn{3}{|c|}{ One-year Horizon } & & & & \\
\hline & 1-month & 6-month & 1-year & 5-year & intercept & slope & curvature \\
\hline Monetary shocks & $1.34 \%$ & $1.68 \%$ & $3.87 \%$ & $9.48 \%$ & $1.60 \%$ & $8.75 \%$ & $19.40 \%$ \\
\hline \multirow[t]{3}{*}{ Output shocks } & $18.88 \%$ & $20.25 \%$ & $20.47 \%$ & $15.21 \%$ & $18.58 \%$ & $3.50 \%$ & $2.01 \%$ \\
\hline & \multicolumn{3}{|c|}{ Two-year Horizon } & & & & \\
\hline & 1-month & 6-month & 1-year & 5-year & intercept & slope & curvature \\
\hline Monetary shocks & $0.07 \%$ & $0.30 \%$ & $0.00 \%$ & $1.22 \%$ & $0.60 \%$ & $13.12 \%$ & $7.03 \%$ \\
\hline Output shocks & $13.66 \%$ & $13.60 \%$ & $11.16 \%$ & $2.12 \%$ & $14.30 \%$ & $27.23 \%$ & $10.33 \%$ \\
\hline
\end{tabular}

Note: Table 1 displays the estimated fraction of the one-month-ahead, three-monthahead, one-year-ahead and two-year-ahead conditional bond-yield variances attributable to monetary-policy innovations and output shocks. For each forecasting horizon results are displayed for one-month, six-month, one-year and five-year nominal bond as well as the computed level, slope and curvature of the yield curve. Intercept, slope and curvature are calculated from regressing one-month, three-month, six-month, one-year, two-year, threeyear, four-year and five-year nominal bond yields on a constant, maturity, and squared maturity. Data of bond yields are extracted from Fama bond files in CRSP. Data period is from 1967:01 to 1998:12. 
Figure 1: Responses of Macroeconomic Variables to Macro Shocks
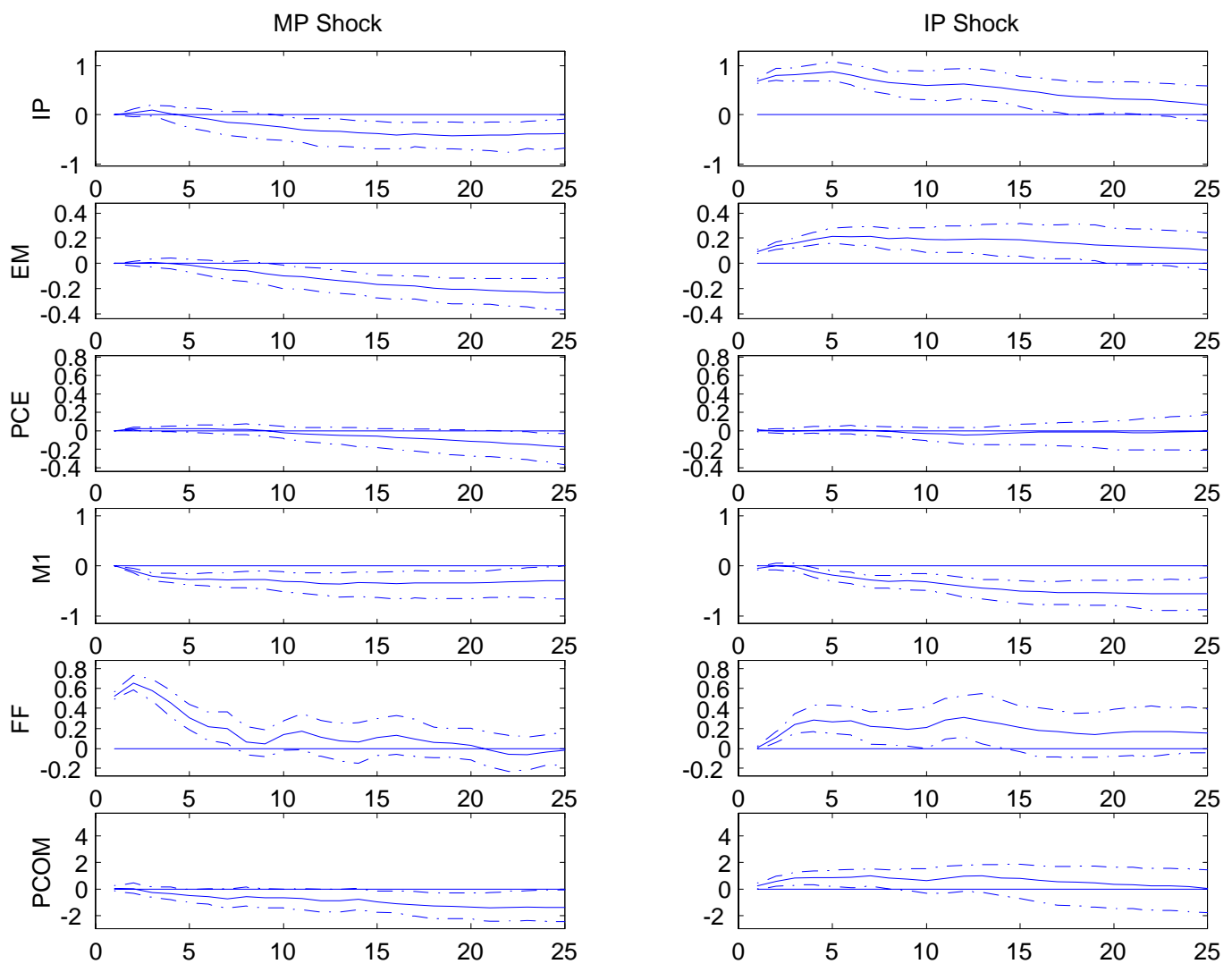

Note: Figure 1 displays the impulse responses of macro variables to one-standarddeviation macro shocks in the empirical VAR study. IP, EM and PCE denote the logarithms of industrial production, nonagricultural payroll employment and the PCE deflator, respectively. M1 represents the logarithm of the monetary aggregate, FF is the federal funds rate, and PCOM stands for the smoothed change in index of sensitive materials prices. Data period is 1967:01-1998:12. The VAR is estimated with lags of twelve months. For IP, EM, PCE, M1 and PCOM, the impulse responses are in units of percentage deviations from the steady state. For the federal funds rate FF, the units are percentage points per annum. The solid lines plot the point estimates for the impulse responses, and the dashdot lines give 95\% confidence bands obtained from Bayesian Monte Carlo method. 
Figure 2: Responses of Bond Yields to Macro Shocks
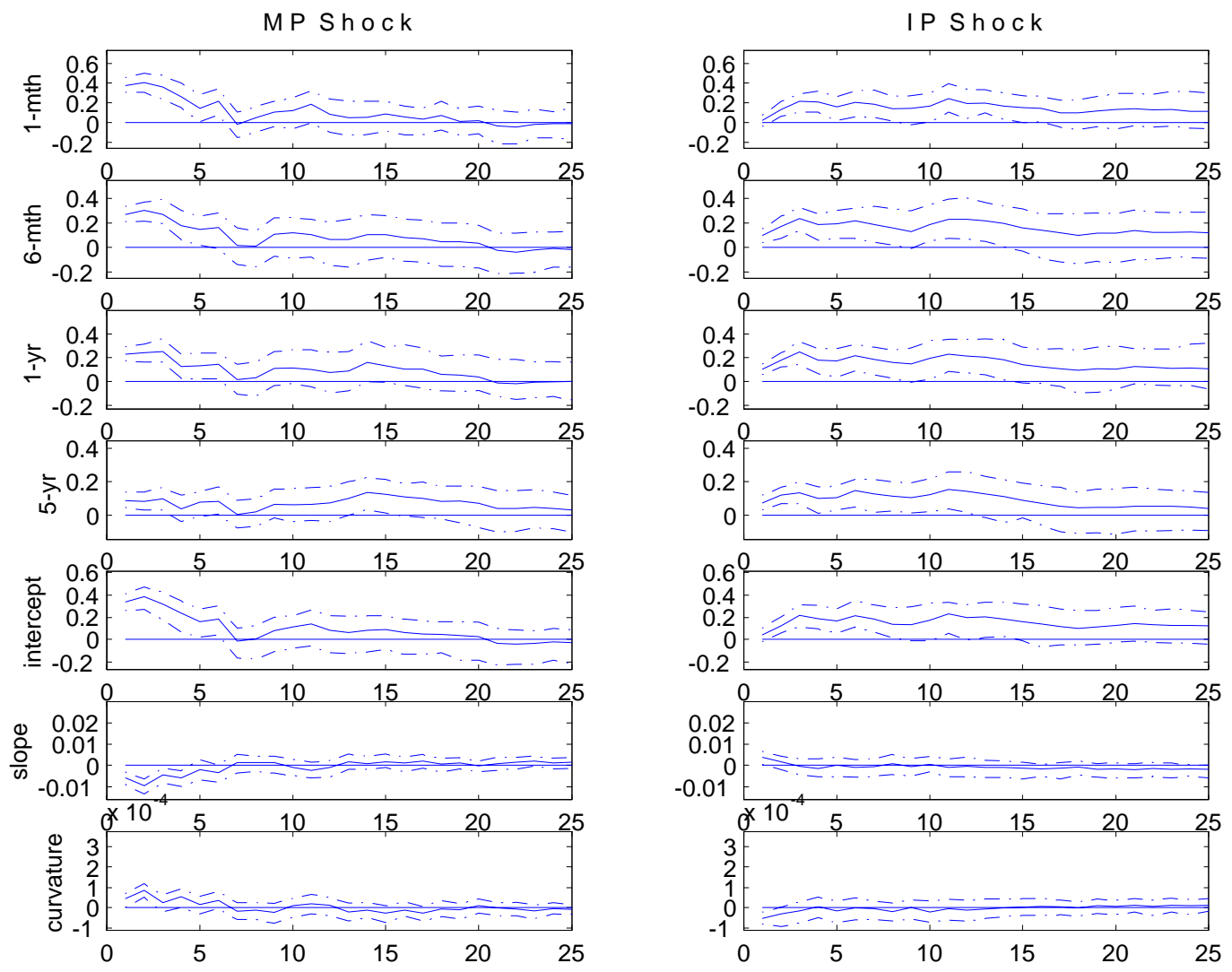

Note: Figure 2 displays the impulse responses of one-month, six-month, one-year and five-year nominal bond yields as well as those of the yield-curve descriptors to onestandard-deviation monetary-policy and real output shocks in the empirical VAR study. The yield-curve descriptors intercept, slope and curvature are computed as described in Section 2.2. Data period is 1967:01-1998:12. The VAR is estimated with lags of twelve months. The first column displays impulse responses to a one-standard-deviation monetary contraction, and the second column displays the impulse responses to a positive, onestandard-deviation real output shock. For the impulse responses of the bond yields, the units are percentage points per annum. The solid lines plot the point estimates of the impulse responses, and the dashdot lines give $95 \%$ confidence bands. 